\title{
Abortion and Unmet Family Planning Needs: A Case Study in Java Provinces, Indonesia, 2020
}

\author{
Liliek Pratiwi ${ }^{1, *}$, Harnanik Nawangsari ${ }^{2}$ \\ ${ }^{1,2}$ Lecturer of Faculty of Health Sciences, Universitas Muhammadiyah, Cirebon, Lecturer of STIKES Insan Cendekia \\ Medika Jombang, \\ *Corresponding author.Email:Liliekpratiwi23@gmail.com,
}

\begin{abstract}
Background: Women with unmet contraceptive needs rarely say that they do not realize the importance of contraceptives since they typically do not have access to contraceptives sources or supply or the price is unaffordable for them. In most countries, married women who ever experience side effects from contraceptives and have health risks prefer not to use it. For decades, advocates, health professionals, policymakers, and funding agents have used information about unmet needs for contraceptives to identify kinds of investments needed in family planning programs to help the development of the country. By helping women prevent unwanted pregnancies, those invented programs can reduce unwanted births and unsafe abortions, thereby improving the health of mothers and children. This can contribute to other development goals, such as reducing the poverty rate and slowing population growth. The importance of using contraception to regulate fertility has been recognized globally. This is a key aspect of reproductive health for women who want to limit their pregnancy rate. Purpose: This study aims to analyze abortion rate and percentage of unmet need in Java provinces, Indonesia, in 2020. Method: This study uses cross sectional to analyze data from Indonesia Demographic and Health Survey conducted in 2018, reports on contraceptive services of National Population and Family Planning Board (BKKBN), and Statistics Indonesia. The data were taken from all Java provinces, which are West Java, Central Java, and East Java. The statistical test used in this study was a linear regression to test the relationship between abortion and unmet need. Results and Discussion: Unmet need is a complex measure. It has been a debate for years among experts on demographic surveys and public health; on how can these happen, is it about by health care factor or about intentions and motivations of women or couples themselves.Conclusions: From the population, which is women in Java provinces, the number of unmarried women who are sexually active is smaller than the number of married women is. The majority of women in this study are already married, and social norms often became obstacles in pre-marital sexual activities. Unfortunately, this group has the highest number of unmet need for contraceptives, so health workers and whole community are expected to take part actively, considering that in this era of society, many residents have not met their needs for contraceptives due to various reasons and situations.
\end{abstract}

Keywords: unmet need, abortion, Java province

\section{INTRODUCTION}

Unwanted pregnancy, a major risk factor for abortion and obstetric complications, is considered as one of the most challenging issues in the field of maternal and child morbidity and women's reproductive health globally. As reported in the previous analysis, the percentage of unwanted pregnancies ended with abortion, while the level of adolescent pregnancy varied yet still ended in abortion. Data on populations of abortion In Indonesia showed that women aged 20 years or more were either uneducated or not graduated yet historically had an unwanted pregnancy. Factors related to unwanted pregnancy are multifactorial, including all disciplines such as health care (coverage and effectiveness of family planning programs), health behavior, knowledge of and appropriate use of modern contraceptive methods, socio-culture (perception of fertility and contraceptive), gender rights (sexual harassment), sexual autonomy and women reproduction to use contraceptive and the time and distance of pregnancy. The benefits of modern contraceptives and family planning particularly in protecting women's health and asserting their reproductive rights and the number of unmet family planning needs are still very high in developing countries. The prevalence of unmet need for family planning in most developing countries ranges from 15 to $58 \%$. Women in the age group of $15-19$ years show the highest proportion of unwanted pregnancies with $82 \%$ of unplanned pregnancies. However, women in the age group of 20-24 years have the highest rate of unwanted pregnancies (104 out of 1000 women aged 1544 years). The correct use of modern contraceptives 
remains the best preventive measure to reduce abortion and maternal mortality.

The concept of unmet need for family planning is useful for identifying women who have not used contraceptive methods but may want to use them. Findings from related studies show that unmet need happened because the family planning program is designed to help couples achieve their target reproductive, broader social improvement, economic measures, and development (Westoff\&Bankole, 2002; Casterline \& Sinding, 2000; Sedgh et al., 2007). The studies also discovered that unmet need could directly contribute to reducing maternal and children mortality with an estimated average of 16.877 maternal deaths and 1.1 million children deaths worldwide in 2015. Researchers have identified several reasons why women refusing pregnancy do use contraceptive. Those reasons include women's perception or concern about contraceptives and its side effects, opposition to contraceptives use (from husband, family, and community), poor access to quality family planning supplies and services, and lack of information.

The proportion of individuals that use all forms of modern contraceptives is still low, despite a high knowledge level on family planning even in developing countries. Many researchers believe that solving problems related to unmet need for family planning can reduce maternal mortality by more than $30 \%$. The latest findings also state that up to 214 million women in reproductive age want to delay or limit their pregnancy but do not use modern contraceptives because of the limitations they have.

\section{RESEARCH METHODOLOGY}

This study is a cross sectional study by analyzing data fromIndonesia Demographic and Health Survey conducted in 2018, reports on contraceptive services of National Population and Family Planning Board $(\mathrm{BKKBN})$, and Statistics Indonesia. The data were taken from all Java provinces, which are West Java, Central Java, and East Java. The statistical test used in this study was a linear regression to test the relationship between abortion and unmet need. The number of sample was 160 samples, selected using simple random sampling technique (55 respondents from West Java province, 59 respondents from Central Javaprovince, and 46 respondents from East Javaprovince).

The variables of this study are: prevalence of abortion in West Java, Central Java, East Java provinces as independent variable, and unmet need due to family planning program in West Java, Central Java, and East Java provinces as dependent variable.

\section{RESULTS AND DISCUSSION}

While real progress has been made to increase access to family planning programs globally, unmet family needs in terms of planning for married women, sexually active, not pregnant, and do not want children yet do not use any contraceptive methods are categorized as unmet need which continue to grow. In all Java provinces, $57 \%$ of married women in reproductive age had unmet need for modern contraceptives, which is a modern method of family planning. West Java, Central Java, and East Java provinces were regions with a high prevalence of unmet contraceptive needs with $40 \%, 32 \%$, and $30 \%$ respectively.

From the results, we found that unmet need was found among women who have been married for less than 5 years. This can be associated to the fact that young couples do not have sufficient knowledge about various contraceptive methods available, about access to family planning programs, or they are afraid of the side effects of contraceptive methods. Furthermore, we also found unmet need among women of 19-25 age groups in 2020 in West Java, Central Java, and East Java provinces. Common reasons for this unmet need for contraceptives were lack of knowledge, economic problems, fear of side effects, religious reasons, uncooperative husband, and limited supply and high cost. In national evaluations of family planning programs, unmet need can be an indicator of family planning programs since it shows how well they carry out reproductive health and the quality of life of their families (International Institute for Population Science (IIPS) and Macro International, 2007).

\section{CONCLUSIONS AND SUGGESTIONS}

This study shows that from the population, which is women in Java provinces, the number of unmarried women who are sexually active is smaller than the number of married women is. The majority of women in this study are already married, and social norms often became obstacles in pre-marital sexual activities. Unfortunately, this group has the highest number of unmet need for contraceptives, so health workers and whole community are expected to take part actively, considering that in this era of society, many residents have not met their needs for contraceptives due to various reasons and situations.

\section{REFERENCES}

[1] Yaya S; Ghosa. Prevalence of unmet need for contraceptive and its association with unwanted pregnancy among married women in Angola. Journal Plos. 2018. 13(12). Retrieved from: https://journals.plos.org/plosone/article?id=10.1371/ journal.pone.0209801

[2] Salazar M, San Sebastian M. Violence against women and unintended pregnancies in Nicaragua: a population-based multilevel study. BMC Womens Health. 2014;14:26. Retrieved from: https://bmcwomenshealth.biomedcentral.com/article s/10.1186/1472-6874-14-26

[3] Ajong AB, Njotang PN, Yakum MN, Essi MJ, Essiben F, Eko FEE, et al. Determinants of unmet 
need for family planning among women in urban Cameroon : a cross sectional survey in the BiyemAssi Health District. Yaoundé BMC Womens Health. 2016;16(4):1-8. Retrieved from: https://bmcwomenshealth.biomedcentral.com/article s/10.1186/s12905-016-0283-9

[4] Black AY, Guilbert E, Hassan F, Chatziheofilou I, Lowin J, Jeddi M, et al. The Cost of Unintended Pregnancies (CoUP) in Canada: Estimating Direct Cost, Role of Imperfect Adherence, and the Potential Impact of Increased Use of Long-Acting Reversible Contraceptives. J Obstet Gynaecol Can JOGC J Obstet Gynecol Can JOGC. 2015;37:1086-97. Retrieved from: https://www.ncbi.nlm.nih.gov/pubmed/26637081

[5] World Health Organization (WHO). Family planning/contracepion 2018. Retrieved from: http://www.who.int/mediacentre/factsheets/fs351/en I
[6] United Nations Population Fund (UNFPA). News on Family Planning 2018. Retrieved from: https://www.unfpa.org/family-planning

[7] Finer LB, Zolna MR. Shifts in intended and unintended pregnancies in the United States, 20012008. Am J Public Health. 2014; 104(Suppl 1):1438. Retrieved from: https://www.ncbi.nlm.nih.gov/pmc/articles/PMC401 $\underline{1100 /}$

[8] US Department of Health and Human Services. Healthy People 2020 topics and objectives. Washington, DC: US Department of Health and Human Services; 2010. Retrieved from: http://www.healthypeople.gov/ 2020/topicsobjectives2020/objectiveslist.aspx? topicid $=13$.

[9] Yerpude PN, Jogdand KS, Jogdand MS. A study on determinants of unmet need for family planning among married women in urban slum area. Int $\mathbf{J}$ Recent Trends Sci Tech. 2013;1(8):122-4. 